\title{
Hazards of baby walkers in a European context
}

\author{
Eleni Petridou, Efi Simou, Constantinos Skondras, George Pistevos, Panagiotis Lagos, \\ George Papoutsakis
}

\begin{abstract}
Objectives-To identify conditions related to baby walker injuries in a Greek population.

Design-Analysis of all baby walker related injuries recorded during a 12 month period by the childhood injury surveillance system established in one of the two teaching hospitals for children serving the population of Athens.
\end{abstract}

Setting-Emergency clinics of A Kyriakou Children's Hospital in Athens, Greece.

Subjects-49 babies with baby walker related injuries brought to the emergency clinics during the period May 1994 to April 1995.

Center for Research and Prevention of Injuries among the Young, Department of Hygiene and

Epidemiology, Athen University Medical School, Athens, Greece and Department of Epidemiology,

Harvard School of Public Health, Boston, USA

E Petridou

Center for Research and Prevention of Injuries among the Young, Department of Hygiene and Epidemiology, Athens University Medical

School, Athens, Greece

E Simou

First Department of Surgery, Aglaia

Kyriakou Children's

Hospital, Athens,

Greece

C Skondras

Second Department of Orthopedics, Aglaia Kyriakou Children's Hospital, Athens,

Greece

G Pistevos

Hellenic Pediatric Society, Athens, Greece

P Lagos

Directorate General, Ministry of Health and Welfare, Athens,

Greece

G Papoutsakis

Correspondence and reprin requests to: Dr Eleni Petridou, Department of Hygiene and Epidemiology, Athens University Medical School, $75 \mathrm{M}$ Asias str, Athens 11527, Greece.
Results-The incidence of these injuries was 16 per thousand person years of users, or 3.5 per thousand babies per year. More boys than girls were brought to the hospital for these injuries and the incidence 10th month of age. Falls from heights, particularly stairs, were the most frequent cause of baby walker related injuries, especially among younger babies. The majority of these injuries were of minor severity, but three babies had bone fractures and one had a second degree facial burn. Six babies required hospitalization and for seven others, a follow up visit was needed. The higher proportion of hospitalization among girls than boys raises the possibility that boys with minor injuries are more frequently brought to the hospital.

Conclusions-Baby walkers impart a significant risk of injury from a consumer product that provides no clearly identifiable benefit. As most baby walker injuries happen on stairs, modifications in product design are required to reduce these injuries. Moreover, parents should be forcefully advised of the risks and predisposing conditions, if baby walkers are to be used at all.

(Injury Prevention 1996; 2: 118-120)

Keywords: baby walkers, hazards, consumer products, health professionals.

Baby walkers give busy parents more freedom during a period when the infant or young child (usually 6 to 17 months old) requires continuous attention. ${ }^{12}$ The popularity of baby walkers was also enhanced by the assumption that they might facilitate walking capacity. It density was highest during the ninth and has been pointed out, however, that baby walkers can contribute to injuries because they provide conditions for increased mobility and speed at an age when the baby is not developmentally ready for this function..$^{3-7}$ Studies in North America, as well as northern and central European countries, have indicated that the incidence of baby walker related injuries is unacceptably high. Rates approaching 10 injuries per thousand infants per year have been reported. ${ }^{1489}$

The problem has not been adequately studied in other countries of the world, especially southern European countries, where environmental conditions, sociocultural values, and child raising habits are somewhat different. We have undertaken this study in Athens, Greece to ascertain whether baby walkers represent an important cause of injuries among babies aged up to 17 months and to identify characteristics of the events and of their consequences.

\section{Methods}

The Center for Research and Prevention of Injuries among the Young (CEREPRI) was established by the Ministry of Health and Welfare and the Department of Hygiene and Epidemiology, University of Athens Medical School for the investigation of the causes and the prevention of childhood accidents. An important data base (injury surveillance system) developed at CEREPRI in collaboration with Aglaia Kyriakou Children's Hospital covers all children with injuries who contact the emergency department of this hospital one of the two university hospitals for children in the Athens area. This hospital includes about $40 \%$ of all childhood admissions. Although there are no figures for cause specific hospital contacts, the alternate shifts between the emergency clinics of the two teaching hospitals suggest near equal rates in these institutions. Only $20 \%$ of emergencies are handled in other health care facilities in the area. During the 12 month period, May 1994 to April 1995, all guardians of children who contacted the emergency department for unintentional injuries were interviewed in person by one of four collaborating interviewers and a standard form was completed. Children are almost always escorted by a guardian when they visit the hospital and there were no refusals.

The data were coded and entered in the computerized data base at CEREPRI. Conditions and other parameters of injuries were coded according to the European Home and Leisure Accident Surveillance System (EHLASS), the Nordic Medico Statistical Committee (NOMESCO) system, and ICD9CM. 
For the purpose of the present study guardians of 200 children ( 18 to 23 months old) who also contacted the outpatient clinics of the same hospital for any condition other than an injury during the same study period were asked whether, and for how long, they have made use of baby walkers. The analysis was done through simple cross classification of the data and application of the $\chi^{2}$ test.

\section{Results}

The table shows the distribution of the 49 children with baby walker related injuries according to the conditions and consequences of the injuries and the demographic characteristics of the victim. The majority of injuries were minor but there were also two cases with bone fractures and another with a second degree facial burn. Six children had to be admitted to the hospital, whereas for another seven a follow up visit was required.

More boys than girls were brought to the hospital with baby walker related injury and the occurrence rate appears to be higher between 9 and 10 months than during the preceding three month period or the next seven month period. By far the most frequently affected body part was the head. Falls from heights are the dominant cause, but falls on the same level are also common. The most common site was stairs, inside or outside the house.

Among the 38 children aged up to 10 months, $29(76 \%)$ suffered their injury on stairs; the corresponding proportion among older babies was four out of $11(36 \%)$. The difference is statistically significant $(p<0.05)$. Only one of the 30 boys who were brought to hospital was admitted, whereas five of the 19 girls were eventually admitted $(p=0.02)$. No other cross classification yielded statistically significant results except those reflecting obvious processes such as severity of injury in relation to admission, or site of injury, and contributing objects. In particular, there was no association of gender with either type of injury or affected body part.

\section{Discussion}

Many consumer products meet real or perceived needs but occasionally they create risks that are not recognized until the cases take the form of a small epidemic. The identification of risk and the evaluation of its magnitude is necessay for the consumer to make an informed decision by taking into account the risks and benefits associated with the use of a particular product. There is. no published scientific evidence that baby walkers advance the baby's ability to walk, but many parents nevertheless welcome the use of these devices, because they keep the child occupied and allow them some additional freedom of movement. ${ }^{1310-12}$

Approximately 35000 babies are born every year in Athens, $40 \%$ or 14000 in the catchment area of the collaborating hospital. In the sample of non-injured children who contacted the hospital, about two thirds used baby walkers for an average of four months; thus the study
Distribution of children with baby walker related injuries according to the conditions and the consequences of the injury and demographic characteristics of the victim

\begin{tabular}{|c|c|}
\hline Variable & No $(\%)$ \\
\hline \multicolumn{2}{|l|}{ Gender } \\
\hline Male & $30(61 \cdot 2)$ \\
\hline Female & $19(38 \cdot 8)$ \\
\hline \multicolumn{2}{|l|}{ Age (months) } \\
\hline$<8$ & $19(38 \cdot 8)$ \\
\hline $9-10$ & $19(38.8)$ \\
\hline $11+$ & $11(22 \cdot 4)$ \\
\hline \multicolumn{2}{|l|}{ Injured body part` } \\
\hline Skull & $23(46 \cdot 9)$ \\
\hline Face & $21(42 \cdot 9)$ \\
\hline Other & $5(10 \cdot 2)$ \\
\hline \multicolumn{2}{|l|}{ Type of injury* } \\
\hline Fracture & $3(6 \cdot 1)$ \\
\hline Burn & $1(2 \cdot 0)$ \\
\hline Abrasion & $11(22 \cdot 5)$ \\
\hline Contusion, bruise, open wound & $21(42 \cdot 9)$ \\
\hline None & $13(26 \cdot 5)$ \\
\hline \multicolumn{2}{|l|}{ Mechanism of injury } \\
\hline Fall from height & $35(71 \cdot 4)$ \\
\hline Fall on the same level & $11(22.5)$ \\
\hline Burn & $1(2 \cdot 0)$ \\
\hline Other & $2(4 \cdot 1)$ \\
\hline \multicolumn{2}{|l|}{ Place of injury } \\
\hline Stairs outdoors & $27(55 \cdot 1)$ \\
\hline Stairs indoors & $6(12.2)$ \\
\hline Kitchen, bedroom & $10(20 \cdot 5)$ \\
\hline Other & $6(12 \cdot 2)$ \\
\hline \multicolumn{2}{|l|}{ Causal object } \\
\hline Stairs & $33(67 \cdot 3)$ \\
\hline Baby walker & $5(10 \cdot 2)$ \\
\hline Hot water & $1(2 \cdot 0)$ \\
\hline Other & $10(20 \cdot 5)$ \\
\hline \multicolumn{2}{|l|}{ Emergency department } \\
\hline Surgery & $43(87 \cdot 8)$ \\
\hline Ear, nose, and throat & $3(6 \cdot 1)$ \\
\hline Orthopedics & $2(4 \cdot 1)$ \\
\hline Eye sight & $1(2 \cdot 0)$ \\
\hline \multicolumn{2}{|l|}{ Outcome } \\
\hline Hospital admission & $6(12 \cdot 2)$ \\
\hline Outpatient treatment (follow up) & $7(14 \cdot 3)$ \\
\hline Outpatient treatment (no follow up) & $7(14 \cdot 3)$ \\
\hline No treatment & $29(59 \cdot 2)$ \\
\hline
\end{tabular}

*When there was more than one injury or they affected more than one body part, the distribution was based on the most serious injury.

base that generated the 49 cases equals approximately 3000 person years $(14000 \times 0.66 \times$ $0.33)$. The incidence of baby walker injuries is, therefore, 16 per thousand person years of users, although patterns and extension of use in the study base cannot be accurately measured. In the total population-among all babies, including non-users - the incidence of baby walker related injuries is approximately 3.5 per 1000 person years. Proportionally, baby walker related injuries represent 49 of a total 3111 injuries among babies 6 to 17 months old seen in the emergency clinics of the hospital during the study period.

The risk from the use of baby walkers was identified more than 20 years ago. ${ }^{346713}$ Since then several studies in North American and European countries have evaluated the characteristics of these injuries. ${ }^{14-12}$ Variability in study design and referent populations make it difficult to compare results across studies and populations groups. It appears, however, that there is substantial variability in the frequency and severity, with higher rates reported from the USA ${ }^{711}$ and Canada ${ }^{4}$ and lower rates from the Netherlands ${ }^{1415}$ and Norway. ${ }^{16}$ The incidence of baby walker related injuries appears to be greater among boys and among babies 8-11 months old. ${ }^{513}$ Most of the injuries of this type occur after a fall on the stairs even in the presence of a supervising adult. ${ }^{51819}$ The results of the present investiga- 
tion, the first to be undertaken in Greece, and one of the very few in southern European countries, suggest that the incidence of baby walker related injuries is relatively high in Athens perhaps because most residents of this city live in multifloor apartment buildings.

The profile of these injuries is similar in the population of Athens as in other populations where the phenomenon has been studied. The frequency of baby walker related injuries that require hospital contact is higher among babies with a mean age of 9 months, ${ }^{517}$ possibly because at this age babies can walk assisted but are unable to control the relatively high speed and sudden and rapid movements of the walker. In agreement with international experience, the large majority of baby walker related accidents occur on stairs, but falls at the same level are also common. ${ }^{3-51819}$ The most frequently affected body part in this study, as well as in other population groups, was the head, ${ }^{341319}$ possibly because this is the protruding body part in most falls, and body mass is greater in the upper half of the body in the first 18 months of life.

An unexpected finding was that the severity of these injuries, as indicated by hospitalization, was higher among girls than among boys. One explanation may be that victims with injuries of minor severity are more frequently brought to hospital when they are boys. Such a differential hospital contact has been noted with respect to minor surgical operations in Greece, ${ }^{20}$ but an interpretation based on gender bias alone is countered by the fact that the male to female ratio was not higher in the present study than in most studies in other populations. ${ }^{513}$ An alternative is that the higher incidence of these injuries in boys reflects an element of male overactivity that may be selectively associated with minor injuries. Greater severity of baby walker injuries among girls has also been reported by other investigators. ${ }^{18}$

\section{IMPLICATIONS FOR PREVENTION}

The results of the present study indicate that injuries from baby walkers are relatively frequent in Greece, possibly because the risks inherent in the device are compounded by the crowding of large segments of the Athenian population in multifloor buildings. The American Academy of Pediatrics has gone so far as to recommend banning movable baby walkers in the USA. ${ }^{21}$ Yet, it seems at present more feasible in Greece to bring the problem to the attention of the health professionals and to educate the public about the risks involved in the use of baby walkers, while working with the European Association for the Co-ordination of Consumer Representation in Satandardization (ANEK) to establish standards for manufacturing safer baby walkers. Experience in Canada, where baby walkers cannot be sold unless they are too big to go through a standard door, provides a useful model.

We are grateful to Sara Levene at the Child Accident Prevention Trust for her advice and to the vising nurses $G$ Chatzi, D Chatzipanagiotou, I Karouti, and E Psaropoulou, who performed the interviews for the Childhood Accident Surveillance Program of CEREPRI. This study has been partly supported by the Hellenic Ministry of Health and Welfare and it was conducted in the context of the Greek European Home and Leisure Accident Surveillance System.

1 US Consumer Product Safety Commission. Baby walker injuries: hazard analysis, NIC-1508-74-H0O3. Washington DC, Bureau of Epidemiology, April 1974.

2 Laffoy M, Fitzpatrick P, Jordan M, Dowdall D. Attitudes to and use of baby walkers in Dublin. Injury Prevention

3 Fazen LE III, Felizberto PI. Baby walker injuries. Pediatrics 1982; 70: 106-9

4 Stoffman JM, Bass MJ, Fox AM. Head injuries related to the use of baby walkers. Can Med Assoc f 1984; 131: 573-5. 5 Rieder MJ, Schwartz C, Newman J. Patterns of walker use and walker injury. Pediatrics 1986; 78: 488-93.

6 Gleadhill D, Robson W, Cudmore R, Turnock R. Baby walkers ... time to take a stand. Arch Dis Child 1987; 62: 491-4.

7 American Medical Association, Chicago, Board of Trustees. Use of baby walkers. Am $\mathcal{f}$ Dis Child 1991; 145: 933-4.

8 Chiavello CT, Christoph RA, Bond RG. Infant walkerrelated injuries: a prospective study of severity and
incidence. Pediatrics 1994; 93: $974-6$.

9 Simpkiss MJ, Raikes AS. Problems with the excessive use of baby-walkers [letter]. Lancet 1972; I: 747.

10 Crouchman $M$. The effects of baby-walkers on early locomotor development. Dev Med Child Neurol 1986; 28: 757-61.

11 Kauffman IB, Ridenour M. Influence of an infant walker on onset and quality of walking pattern of locomotion: an electromyographic investigation. Percept Mot Skills 1977 45: $1323-9$.

12 Ridenour MV. Infant walkers: developmental tool or inherent danger. Percept Mot Skills 1982; 55: 1201-2.

13 Kavanagh C, Banco $L$. The infant walker - a previously unrecognized health hazard. $A m \mathcal{F}$ Dis Child 1982; 136: 205-6.

14 Engel M, Viot I. Baby-walkers - risk analysis and prevention. Amsterdam: Consumer Safety Institute, 1989.

15 Privé Ongevallen Registrarie Systeem. Annual report on home and leisure accidents in the Netherlands. Amsterdam: home and leisure accidents in the Netherlands. Amsterdam: 1994-1995).

16 National Institute of Consumer Research. Accidents on baby-walkers. Report to Secretariat European de Coordination pour la Normalisation. Norway 1994.

17 Berger L. Childhood injuries: recognition and prevention. Curr Probl Pediatr 1981; 12: 1-59.

18 Coats TJ, Allen M. Baby walker related injuries - a continuing problem. Arch Emerg Med 1991; 8: 52-5.

19 Partington MD, Swanson JA, Meyer FB. Head injury and the use of baby walkers: a continuing problem. Ann Emerg Med 1991; 20: 652-4.

20 Petridou E, Valadian I, Trichopoulos D, Skalkidis Y, Katsouyanni K, Matsaniotis N. Social factors and professional attitudes as determinants of the frequency of small surgical procedures among children in Greece. Sozial Praventivmedizin 1986; 31: 308-12.

21 Committee on Injury and Poison Prevention. Injuries associated with infant walkers. Pediatrics 1995; 5: $778-80$. 